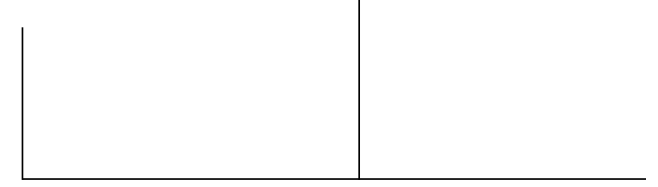

Rev. Latinoam. Psicopat. Fund., IV, 1, 168-174

\title{
Entrevista com Pierre Fédida
}

(Concedida a Paulo Roberto Ceccarelli em Paris, no dia 27 de julho de 2000)

Há algum tempo o Sr. tem utilizado a expressão Psicopatologia Fundamental. Gostaria que o Sr. falasse um pouco do por que da escolha desse termo e também de sua história.

A criação da expressão "Psicopatologia Fundamental" ocorreu-me, após muitas considerações, há mais ou menos 15 anos. Inicialmente graças ao lugar que tinha, no passado, a Psicopatologia Geral, com a publicação por Jaspers, em 1913, de sua "Psicopatologia Geral". Naquela época falava-se também, inclusive na França, de "Psicopatologia Patológica". Ocorreume, então, por várias razões, a idéia de propor o termo de "Psicopatologia Fundamental".

Já nos anos 1980 observa-se um enfraquecimento da psiquiatria graças ao desenvolvimento das neurociências, tal como elas se apresentam hoje, mas sobretudo ao extraordinário impulso da farmacologia. E se a psiquiatria se enfraquece, paradoxalmente a psicanálise também se enfraquece. Preocupei-me, então, em incentivar a Psicopatologia Fundamental criando, inicialmente, um Laboratório e, em seguida, uma formação de doutorado em Psicopatologia Fundamental. Gostaria ainda de tecer algumas considerações sobre o enfraquecimento da psiquiatria. Inicialmente um tal enfraquecimento se deve ao desaparecimento da psicopatologia na psiquiatria. A partir 


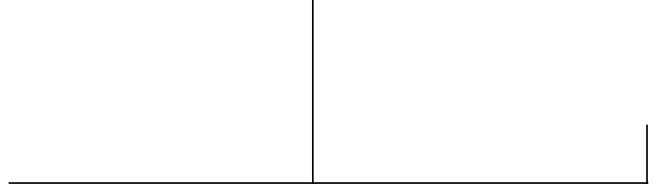

daí, a psiquiatria deixa de ser uma abordagem, uma disciplina clínica, como havia sido até então, para se tornar uma pragmática da prescrição: prescrição social, medicamentosa.

É aí que entram os DSMs?

Sim. O DSM é um manual que visa uma nova classificação das doenças mentais. Sua maior preocupação é a epidemiologia e a categorização dos problemas mentais; não é uma psicopatologia.

É nesse sentido que o Sr. vê o risco do enfraquecimento da psiquiatria?

Justamente. Exemplos não faltam: pode-se tratar a depressão, que é polivalente, por meio de medicamento, por meio das moléculas que são cada vez mais inteligentes, sem que seja necessário conhecer os conflitos interiores e as experiências psíquicas do indivíduo. Nessa perspectiva, nem a psicopatologia nem a clínica são necessárias: basta conhecer o uso das moléculas químicas.

A evolução da psicopatologia seguia duas direções principais: ela continuava em contato com a prestigiosa tradição da psicopatologia antes mesmo da criação deste termo; ou seja, a experiência que o terapeuta adquire a partir do sofrimento do doente. Por isso, sempre dei muito valor à noção (esquiliana) de patei mathos: aquilo que o sofrimento ensina. Muitos tratados de filosofia e de medicina insistem sobre a importância da experiência da doença mental do outro como fator central da observação e da compreensão do clínico. Nesse sentido a psicopatologia fundamental aproxima-se da psicopatologia freudiana. Freud segue as proposições da psiquiatria de seu tempo - ele utiliza as mesmas noções da psiquiatria da época: melancolia, parafrenia, paranóia etc. - mas vai trabalhar essas noções a partir de uma metapsicologia e, naturalmente, a partir também das descobertas que a prática clínica lhe proporciona. Assim, a noção de "Psicopatologia Fundamental” não está muito distante da idéia de que, em psicanálise, a psicopatologia é psicopatologia fundamental e não psicopatologia geral. Esse ponto de vista é extremamente importante para diferenciar algo que ocorre na Alemanha e nos países de língua germânica por volta dos anos 1920: de um lado um desenvolvimento filosófico - tal como Binswanger e outros tantos, na França Minkowisky - que propõe que a psicologia acadêmica seja repensada a partir da fenomenologia. Essa mesma posição filosófica vai levar à Psicopatologia Fenomenológica, corrente bastante importante seguida por diversos autores, que terá grande influência na análise existencial.

Por outro lado, também nos anos 1920, Freud mantém as referências à psicopatologia, mas cria a metapsicologia. Como isso, não é necessário recriar a psiquiatria. Para Freud, o importante era compreender a fundo a expressão dos sintomas. Sobre esse ponto ocorreu uma divisão curiosa entre aquilo que nos EUA é 
chamado de "psicopatologia filosófica”, hoje representada pela “Teoria da Mente” - Theory of Mind - em que se privilegia o fenômeno e não o sintoma; e, por outro lado, a "psicopatologia analítica" - para Freud a "psicopatologia da vida cotidiana". A expressão "Psicopatologia Fundamental", e este é o segundo ponto que quero evocar, deve-se igualmente ao fato de que, em 1985, pareceu-me de suma importância manter uma formação em psicopatologia para todos aqueles que trabalham na saúde mental: psiquiatras, psicólogos... Sem essa formação, o risco do desaparecimento da psicopatologia seria grande. Ao mesmo tempo, pareceu-me igualmente importante de se pensar no futuro, ou seja, de discutir os modelos, os paradigmas que nos afetam, que é nosso objeto de referência, nas teorias e práticas bastante diferentes, como é o caso, por exemplo, da ciência cognitiva e da psicanálise. "Fundamental”, neste ponto, separa-se da psicanálise para marcar que se trata de uma psicopatologia que propõe uma reflexão crítica dos modelos existentes.

Quais seriam, então, as bases para um diálogo entre a Psicopatologia Fundamental e a Psiquiatria?

Bem, acho que já falei sobre alguns aspectos dessa questão. Mas gostaria de retomar a história da psiquiatria, particularmente com Kraepelin, mas também com Bleuler, e com todos aqueles que, na França, participaram no desenvolvimento da psiquiatria. Aqui é importante lembrar que por muito tempo, praticamente até os anos 1950 e 1960, muitos psiquiatras tinham a preocupação de definir a vocação antropológica da psiquiatria. Ademais, a psiquiatria não fazia totalmente parte da medicina, embora seja necessário ser médico para ser psiquiatra. A psiquiatria solicitava a participação das Ciências Humanas, da mesma forma que das Ciências da Vida, marcando sua vocação antropológica. O lugar que a psiquiatria ocupava era bastante singular. Essa perspectiva - de dar fundamentos antropológicos à psiquiatria - foi em parte abandonada diante da recente evolução das disciplinas científicas. Além disso, em psiquiatria é cada vez menos necessário - e não se tem mais tempo! - escutar os pacientes como outrora e ouvir suas histórias para compreender o desenvolvimento da doença. O uso dos meios prescritivos tendem, cada vez mais, a fazer do psiquiatra um clínico rápido, um “clínico express”. Ele não segue mais a evolução da doença até que o delírio cesse ou até que os sintomas desapareçam e o paciente pode ser considerado psiquiatricamente curado. Então, para responder a sua pergunta sobre o lugar da psicopatologia fundamental na psiquiatria, acho que seu lugar é essencial: trata-se não mais de retomar a psicopatologia geral, mas, antes, de saber qual é o nosso modelo de trabalho quando tratamos de um paciente. Na psicopatologia fundamental, dou grande importância à evolução dos sintomas sob a influência de medicamentos. Por exemplo, um paciente que não está mais deprimido, porque toma um antidepressivo, tem uma nova patologia. 


\section{EN TREVISTAS}

Ele não está curado; ele está curado psiquiatricamente, mas tem uma nova patologia. Então, eu repito, o uso de moléculas químicas hoje em dia é cada vez mais difícil, pois as moléculas são cada vez mais poderosas; eu diria mesmo inteligentes: os psicotrópicos são extremamente inteligentes. É neste ponto que se impõe a necessidade para a psicopatologia fundamental de um diálogo com a psicofarmacologia. Esse diálogo, na França, aconteceu com um neurofarmacólogo que se chama Claudewsky no Collège de France, e sobretudo com as equipes de psiquiatria de Widlöcher e, mais recentemente, com a equipe de Guillotat em Lion.

Como o Sr. definiria o adoecer na contemporaneidade? Como as mudanças da atualidade, como a nova referência de tempo trazida pela internet, como tudo isso modificou não só o adoecer como também a procura de ajuda terapêutica?

Bem, essa é uma questão difícil por sua generalidade. Tornou-se muito difícil manter as grandes referências tal como nós dispomos em psicopatologia - por exemplo, a diferença entre neurose obsessiva, funcionamento obsessivo, histeria, fobia... Além disso, tenho algumas restrições quanto à noção de modernidade. Mas tentarei responder mais diretamente à sua pergunta. É verdade que assistimos a uma mudança de civilização, e uma tal mudança leva a outros meios de expressão, de comunicação, de adaptação. Voltando, por exemplo, à questão da depressão que é muito interessante. Uma pessoa deprimida é alguém arrasado que deve ser ajudado o mais rapidamente possível para que possa reagir. Ora, não se pode esperar que siga um tratamento psicanalítico para curar a depressão, pois se um tal tratamento der resultado, não será imediatamente. Assim, a maioria das pessoas que sofrem de depressão, e que necessitam de uma recuperação rápida, tende a privilegiar um tratamento curto, seja psiquiátrico ou psicoterapêutico.

Sem dúvida, estamos em presença de novos dados, ou seja, na cultura, na civilização, a situação não é mais a mesma do começo do século vinte quando se procurava um psicanalista para compreender as origens dos conflitos e tratar a neurose. Hoje procuram-se soluções rápidas para o sofrimento. A questão colocada, para ser amplamente respondida, levaria a uma outra questão que não tratarei aqui: o futuro da psicanálise nesta mudança de civilização.

A mudança de civilização é sentida quando é possível se comunicar, em tempo real, com alguém a 10 mil, a 15 mil km de distância daqui. Esta mudança também se faz notar quando a leitura de uma obra, de um livro, é substituída por uma informação que está imediatamente disponível, enfim, quando o modo de comunicação entre humanos passar a ser influenciado pelo conjunto dos elementos presentes no novo contexto da civilização. Ao mesmo tempo, uma observação mais atenta revela um fenômeno interessante que me foi relatado por um grupo de psiquiatras que trabalha em meio rural. Veja bem, em meio rural e não nas grandes aglomerações. 
Nas estruturas montadas para oferecer um atendimento rápido, os pacientes têm sentido a necessidade de falar; a necessidade de um profissional que possa darlhes atenção e escutar suas demandas. Isso significa a necessidade de criar-se um espaço em que exista tempo para falar. Seria interessante uma pesquisa para se saber qual a influência da psicanálise nas transformações dos sujeitos que se submeteram a uma análise. Existe, com efeito, na atualidade, uma aceitação de um novo modo de pensamento, mas, ao mesmo tempo, uma demanda pela compreensão de relações singulares.

Para terminar, gostaria que o Sr. falasse um pouco sobre a relação entre psicanálise e neurociências.

Antes de responder a essa questão, gostaria ainda de dizer algo sobre a relação entre o enfraquecimento da psiquiatria e o declínio da psicanálise. A psiquiatria, no sentido clínico e na sua melhor tradição, nunca se opôs à psicanálise, ainda que os parâmetros de referência não sejam os mesmos. Freud sempre reivindicou o fato de continuar psiquiatra.

A relação da neurociência com a psicanálise é uma questão que merece várias observações. Nos meus contatos com os neurobiologistas “duros”, ou seja, os que trabalham de maneira extremamente científica em seus laboratórios (hard-science), pude inteirar-me do conhecimento que eles desenvolvem sobretudo no campo da neurociência molecular. Esses neurobiologistas, mesmo quando favoráveis à psicanálise, não tentam estabelecer pontes entre neurobiologia e psicanálise. E quando o fazem é para discutir certos aspectos de ordem epistemológica, pois a neurobiologia não necessita diretamente da psicanálise. Por outro lado, alguns geneticistas trabalham com alguns conceitos da psicanálise.

Uma outra observação, que reforça a primeira, é sobre a questão do método. Eu sou pela heterogeneidade: campos que são diferentes, com métodos, objetivos e procedimentos diferentes não se comunicam facilmente. Por exemplo, uma pesquisa no domínio da neurobiologia sobre a doença de Parkinson, ou Alzheimer, e aquilo que a psicanálise tem a dizer sobre o envelhecer, não entram diretamente em comunicação. $O$ fato de que os neurobiólogos que trabalham com a questão do dormir e do sonhar parecem, às vezes, falar as mesmas coisas que os psicanalistas, não significa que estejam, de fato, falando das mesmas coisas. Devemos deixar de lado as ilusões de interdisciplinaridade. Minha experiência do que tem sido feito em Paris, sobretudo no Centre du Vivant (Centro do Vivente) do qual sou o diretor, mostra que a fecundidade dos seminários que temos tido implica que aqueles que dele participam tenham um interesse no trabalho uns dos outros; que fossem o mais inteligentemente informados daquilo que o lado oposto faz. Mas não podemos esperar, visto o estado atual de conhecimento científico e psicanalítico 


\section{EN TREVISTAS}

estabelecer facilmente pontes entre campos tão distintos como a neurociência e a psicanálise.

Uma terceira observação: quando se fala hoje em dia de neurociência, está-se freqüentemente referindo à integração das ciências cognitivas nas neurociências, daí a expressão "neurociência cognitiva”. Como se as ciências cognitivas pudessem fazer a ponte entre a neurociência dura e a psicanálise. Uma vez mais devemos refletir com cuidado entre o que pode ser a realidade de um diálogo e a ilusão de um diálogo. Por exemplo, o "eu” dos neurocientistas não é o mesmo "eu” os psicanalistas. Quarta observação: muitos neurocientistas da atualidade tendem a considerar que a obra pré-psicanalítica de Freud - "As Afasias”, “O Projeto...”, e seu trabalho de pesquisador, que tudo isto formavam a base daquilo que, em seguida, tornou-se a neuropsicologia. Aqui também devemos ter cuidado. Detenhamo-nos em dois aspectos: primeiro que, incontestavelmente, Freud tinha uma escuta extremamente dinâmica do funcionamento psíquico. Em seu trabalho sobre as afasias, no Projeto... ele desenvolveu hipóteses fecundas, embora não tivesse, naquela época, o conhecimento científico que dispomos hoje.

Conseqüentemente, as contribuição do Freud “pré-Freud” são sem dúvida muito interessantes, principalmente para os psicanalistas que têm interesse em compreender como uma obra, um pensamento, é formado, ou ainda, comparar as idéias do Freud do começo com algumas de suas idéias tardias. Mas daí a dizer que Freud abriu a via à neuropsicanálise é uma afirmação da qual desconfio muito. Freqüentemente ouve-se dizer que se a psicanálise edificou-se a partir de modelos científicos atualmente ultrapassados, porque a psicanálise não deveria se reatualizar a partir dos modelos científicos de nossa época? Acho que aqui temos uma nova concepção da psicanálise; mas é importante saber que não se trata mais da psicanálise freudiana. A psicanálise freudiana separou-se dos modelos biológicos e sobretudo dos neurológicos e neuropsicológicos: a metapsicologia freudiana é prova disso. Ou seja, cada vez mais as proposições, as hipóteses, os conceitos, que têm valor ficcional para trabalhar com os pacientes, mas resistem a uma comprovação científica, distanciaram-se desses modelos - biológicos, neurológicos, neuropsicológicos. Devemos prestar muita atenção a isso. Pode-se até falar, como se faz atualmente, de "neuropsicanálise" como uma disciplina. Mas, para mim, uma tal disciplina é incompreensível em termos da psicanálise freudiana. Se alguém disser “a psicanálise freudiana está completamente superada; deve-se ir mais além de Freud; a psicanálise é uma neuropsicanálise”, então, tudo muda. Será que o futuro nos reserva uma nova disciplina armada de novos métodos e, provavelmente, de uma nova concepção da prática analítica? Bem aí é uma outra coisa. A Associação Internacional de Psicanálise desenvolve pesquisas nesse sentido. Mas aqui estamos muito distantes do velho Freud: estamos abandonando-o. Não se deixa facilmente a psi- 
canálise, o freudismo, o kleinismo, o bionismo. De fato, não se procura fazer pontes; trata-se de uma outra coisa.

Bem, Prof. Fédida, muitíssimo obrigado pela entrevista. Há ainda algo que o Sr. gostaria de acrescentar?

Certamente eu teria ainda muita coisa a dizer. Porém direi apenas que acho que se deve estar extremamente interessado por tudo o que acontece, pelos novos desenvolvimentos da psicanálise. Deve-se interessar também, é claro, pela questão bastante atual das psicoterapias. Além disso, acredito que se deve estar sempre muito aberto a toda evolução da civilização. Há muita coisa interessante acontecendo hoje que deve ser acolhida, pensada e trabalhada. Mas, ao mesmo tempo, não podemos nos esquecer das bases que permitem que a psicanálise exista. 